\title{
Políticas Públicas e Desigualdade de Gênero na Sociedade Brasileira: Considerações Sobre os Campos do Trabalho, da Política e da Ciência
}

\author{
JANAÍNA XAVIER DO NASCIMENTO ${ }^{1}$
}

\begin{abstract}
Resumo
O presente texto enfoca a problemática da desigualdade de gênero e políticas públicas na sociedade brasileira, tendo como principais objetivos os que se seguem: Analisar a desigualdade de gênero na sociedade brasileira, traçando um esboço do que ocorre em três áreas centrais para essa discussão, quais sejam: campo do trabalho, campo da representação política e campo científico; 2) Examinar conquistas e desafios no que tange ao enfrentamento dessa desigualdade através de políticas públicas de gênero. Para tanto, recorre-se a dados secundários das seguintes fontes: IBGE, TSE e CNPq. Por fim, observam-se conquistas importantes, contudo não a ponto de reverter significativamente o quadro de desigualdade profunda, sobretudo no campo da representação política.
\end{abstract}

Palavras-chave: Desigualdade de gênero. Políticas públicas. Política. Ciência.

\section{Public Policy and Gender Inequality in Brazilian Society: Considerations From the Realms of Labor, Politics and SCIENCE}

\begin{abstract}
The present text focuses on issues of gender inequality and public policy in Brazil today. My major goals are as follows: 1 ) to provide an analysis of gender inequality in Brazilian society through an examination of the three key arenas of labor, political representation and science and 2) to examine both the advances and the challenges

1 Doutora em sociologia política pela UFSC e professora-adjunta na Universidade Federal de Santa Maria (UFSM), Brasil. E-mail: janainaxn@gmail.com.
\end{abstract}


that persist in confronting inequality through public policies on gender. To these ends, I employ secondary data, obtained from three different official sources (IBGE, TSE and CNPq). Lastly, I argue that while the policies that have been implemented can be linked to significant progress in the three above-mentioned arenas, we are still quite far from a real reversal of the current situation of deep inequality, persisting, above all, in the field of political representation.

Keywords: Gender inequality. Public policy. Politics. Science.

A invisibilidade da desigualdade de gênero em várias instâncias da sociedade brasileira ainda é significativa. Em face das conquistas das mulheres no que tange aos seus direitos sociais e políticos, não é infrequente o desconhecimento do quadro de desigualdade profunda e persistente. Portanto, faz-se necessário lançar luz sobre essa desigualdade. Nesse intuito, as questões centrais a orientar esse trabalho consistem nas que se seguem: como anda a desigualdade de gênero na sociedade brasileira, especialmente nos campos do trabalho, da representação política e da ciência? E como as políticas públicas de gênero têm enfrentado o problema da desigualdade? $\mathrm{O}$ artigo divide-se nos seguintes tópicos: 1) aspectos teóricos e conceituais; 2) aspectos históricos; 3) esboço do quadro de desigualdade de gênero nos campos supracitados, com ênfase final numa reflexão sobre conquistas e desafios. Para análise foram usados dados das seguintes fontes: IBGE, TSE e CNPq.

\section{Políticas Públicas e Gênero: Aspectos Gerais e Conceituais}

\section{DeFinindo CONCEITOS}

A princípio é necessário que o conceito de políticas públicas de gênero seja definido, assim como é também relevante uma redefinição do conceito de cidadania de Marshall. As políticas públicas de gênero estão inseridas no âmbito das políticas públicas sociais, daí porque a definição a seguir corresponde não às políticas públicas no geral, 
mas as políticas sociais em particular. Para Marshall (1967, p. 6), as políticas sociais compreendem políticas de governos "relativas à ação que tem um impacto direto no bem-estar dos cidadãos ao dotá-los de serviços ou renda".

Nessa perspectiva, as políticas públicas de gênero são aqui definidas levando em conta três fatores: sua amplitude ou foco, seu modelo de formulação e, por fim, seu propósito, seja ele emancipatório ou conservador. Em relação ao primeiro fator, trata-se de políticas sociais que incorporam a questão de gênero, o que pode ocorrer com políticas voltadas exclusivamente para as mulheres, ou com políticas mais gerais que incluem as mulheres como beneficiárias em potencial, como é o caso de algumas políticas de combate à pobreza. Em relação ao segundo fator, são políticas públicas cujo modelo de formulação inclui as mulheres apenas como beneficiárias, ou pode ser um modelo no qual as mulheres são além de beneficiárias, formuladoras e executoras, ou seja, assumem um papel de sujeito no processo de formulação e implementação das políticas. Em relação ao terceiro fator, trata-se de políticas que incorporando a questão de gênero podem, por um lado, estar explicitamente comprometidas com a redução da desigualdade entre mulheres e homens e com o empoderamento das mulheres, ou podem ter propósitos conservadores sem qualquer compromisso em se opor à assimetria de poder como, por exemplo, as políticas implantadas no Governo Vargas (BESSE, 1999), o que tem desencadeado a crítica à "funcionalização das mulheres pelo Estado" (ALVAREZ, 2004, p. 103-111).

Além da definição desses conceitos é necessário remeter a um dos debates que tem estado presente em torno das políticas de gênero que diz respeito à necessidade de redefinição do conceito de cidadania moderno, tal como formulado por T.H. Marshall. Não se trata de uma mera discussão conceitual; seus efeitos sobre a política são claros uma vez que cidadania implica, acima de tudo, na conquista e usufruto de 
direitos políticos, civis e sociais, o que, por sua vez, pressupõe a noção de justiça social. Embora a ideia de cidadania não tenha sido inventada por Marshall, estando presente em períodos históricos distintos como na Grécia e Roma antigas, bem como em cidades do Renascimento, é sua definição que tendeu a prevalecer na segunda metade do século XX. Sylvia Walby (2004), ao apontar a ausência da questão de gênero no conceito de Marshall, propõe que às dimensões da cidadania destacadas pelo autor (política, civil e social) sejam incluídos direitos específicos das mulheres de modo a contemplar a questão de gênero, ressaltando que na dimensão política não é suficiente o direito de eleger representantes, sendo igualmente necessária a presença das mulheres nos espaços de poder político. Já em relação aos direitos civis reconhece o papel fundamental da liberdade da pessoa e de liberdade de expressão enfatizados por Marshall, mas enfatiza que para que os direitos civis contemplem as mulheres precisam incluir outros direitos relacionados ao corpo, ao arbítrio e à sexualidade, tais como: "direitos reprodutivos, direito à contracepção e ao aborto, à preferência sexual, e o direito de não sofrer espancamento ou violência sexual" (WALBY, 2004, p. 71). Por fim, também os direitos sociais devem ser ampliados para incluir as mulheres.

Assim, munidas deum forteinstrumento conceitual-cidadania - que não negligencia a questão de gênero, as políticas públicas de gênero são formuladas de modo a incorporar os direitos políticos, civis e sociais, ou os direitos humanos das mulheres. A invisibilidade desses direitos nas políticas públicas em vários momentos e contextos distintos explica, em parte, a razão pela qual as primeiras políticas públicas dirigidas às mulheres as reduziam à condição de "mãe trabalhadora". Contudo, nas últimas décadas, é possível observar uma multiplicação das áreas para quais são formuladas as políticas de gênero: violência, saúde, direitos reprodutivos, educação, sexualidade, geração de emprego e renda, empoderamento, política, entre outras. 
Uma mudança para a qual os movimentos feministas e de mulheres foram fundamentais ao demandar do Estado um posicionamento ativo na promoção da cidadania das mulheres.

Além dos movimentos sociais, agências multilaterais têm desempenhado um papel relevante, fomentando e pressionando os Estados nacionais a impulsionarem o empoderamento das mulheres. Nesse cenário, algumas estratégias no sentido de promoção dos direitos humanos das mulheres tornaram-se mais populares. Refiro-me à criação de organismos institucionais dentro do Estado e às políticas de cotas. Os obstáculos enfrentados por esses organismos institucionais em várias partes do mundo são semelhantes em muitos aspectos, não obstante a inserção dos mesmos em contextos socioculturais distintos. Esses obstáculos referem-se ao fato de que as burocracias governamentais ainda "dão pouco espaço e nenhuma legitimidade ao projeto político de igualdade de gênero" (GOETZ, 1995, p. 51), o que se reverte em limitados recursos humanos e financeiros e numa postura hostil nas rotinas operadas na máquina burocrática.

Por fim, outras estratégias de implementação das políticas de gênero têm sido alvo de debate, como a discussão sobre políticas focalizadas versus políticas transversais. No cenário brasileiro, na agenda atual a estratégia da transversalidade tem sido defendida, entretanto essa é também uma questão sem resposta já que ambas as estratégias representam riscos. Como observado por Alvarez (2004), no caso das políticas focalizadas haveria o risco de "guetizar" ou "marginalizar" questões relevantes para o empoderamento das mulheres. No caso das políticas transversais haveria o risco de "diluir o impacto da intervenção feminista". 


\section{Políticas Públicas de Gênero no Contexto da Globalização}

O processo de globalização econômica, social e cultural introduziu oportunidades e desafios ao feminismo e às políticas de gênero. As oportunidades correspondem, de um lado, à emergência de uma sociedade civil feminista transnacional com novos espaços e formas de lutas (NASCIMENTO, 2005), espaços onde ocorre a transnacionalização dos movimentos sociais (MOGHADAM, 2000; SCHERER-WARREN, 1993), tornados possíveis com a compressão do tempo e do espaço característicos da globalização. Assim, a universalização e o fortalecimento do discurso dos direitos humanos em várias partes do mundo e a defesa de direitos humanos como universais - a despeito das controvérsias envolvendo multiculturalistas e relativistas - tem contribuído para legitimar a agenda feminista desde que a Convenção da ONU em 1979 preconizou a eliminação de todas as formas de discriminação contra as mulheres e, desde que em 1993, na Conferência de Viena, a ONU incorporou as reivindicações dos movimentos feministas e de mulheres, definindo a violência contra as mulheres como violação aos direitos humanos. Além disso, agências multilaterais têm desempenhado um papel importante apoiando a promoção dos direitos humanos das mulheres, ao exercer pressão sobre os Estados nacionais, a fim de que esses formulem políticas públicas de gênero. Na década de 90, com a divulgação de estudos como o Relatório sobre o Desenvolvimento Humano, nos quais se constata o processo de pauperização das mulheres, o Banco Mundial passou a recomendar políticas de combate à pobreza focalizadas nas mulheres. De modo que, tanto as agências multilaterais como o feminismo internacional, têm desempenhado papel fundamental como organismos institucionais de pressão sobre os Estados nacionais no intuito que esses implementem políticas de equidade. 
Já os desafios colocados pela globalização remetem à possibilidade e desejabilidade de universalização dos direitos humanos frente a contextos multiculturais onde a cultura e as tradições apontam para outros valores. Alternativas têm sido apontadas no sentido de uma "concepção multicultural dos direitos humanos" (SANTOS, 2000). O dilema está longe de ser solucionado, contudo, alguns estudos têm demonstrado que no âmbito da prática política feminista há mais avanços do que na filosofia (WALBY, 2004).

\section{Políticas Públicas de Gênero na Sociedade Brasileira: Breve Esboço das Últimas Décadas}

Na década de 80 , as políticas de gênero concentraram-se nas áreas de saúde e de violência contra a mulher. $\mathrm{Na}$ área de saúde, sob o impacto do movimento feminista e de mulheres, foi criado em 1983 o PAISM (Programa de Assistência Integral à Saúde da Mulher) buscando ir além dos programas materno-infantil, habituais nas políticas públicas de saúde desde a década de 30, visando atender a saúde das mulheres em suas várias fases da vida. $\mathrm{Na}$ área de violência contra a mulher foi implantada em 1985 a primeira delegacia de polícia em defesa da mulher no estado de São Paulo. É importante ainda destacar que nesse período, no âmbito de governos de oposição eleitos em 1982 pelo PMDB, surgiram os primeiros organismos institucionais em favor da cidadania das mulheres, isto é, os Conselhos Estaduais da Condição Feminina em São Paulo e Minas Gerais e, em seguida, o Conselho Nacional dos Direitos da Mulher, órgão vinculado ao Ministério da Justiça. Esses organismos correspondem, como atesta a ONU, à "maquinaria estatal" a serviço dos direitos sociais, civis e políticos das mulheres. Não obstante o alcance e eficácia das ações desses Conselhos, posteriormente colocados em xeque por entidades 
feministas, o fato é que essas políticas respondiam a reivindicações dos movimentos feministas e de mulheres.

Contudo, essa década enfrentou grave crise econômica sendo esta uma das principais responsáveis pela redefinição da agenda do Estado caracterizada, em parte, por uma maior divisão de competências entre os governos federal, estaduais e municipais. Com a ampliação de competências dos governos municipais e estaduais no que tange a elaboração e implantação de políticas públicas, ocorreu a inclusão de novos temas nas políticas implementadas, entre os quais estava incluída a questão de gênero (FARAH, 1999, 2004). Entretanto, a incorporação da questão nem sempre foi orientada pela perspectiva de gênero, ou seja, nem sempre caminhou no sentido de reduzir as desigualdades de gênero. Nesse sentido, como argumenta Farah "Há programas que, embora focalizem as mulheres ou a elas dirijam módulos específicos, acabam por reiterar desigualdades de gênero, reafirmando uma posição tutelada e subordinada da mulher tanto no espaço público como no privado"(FARAH, 2004, p. 65).

Na década de 90 as áreas são ampliadas incluindo programas de incentivo à geração de emprego e renda, meninas e adolescentes em situação de risco, apoio às mulheres rurais. Num cenário onde as ONGs se fortalecem tornando-se "parceiras" do Estado e dos movimentos sociais, ganham espaço as políticas afirmativas defendidas por entidades feministas e as políticas focalizadas preconizadas por agências multilaterais, como o Banco Mundial, para combater o processo de pauperização das mulheres. Nesse período, precisamente em 1996, foi criada a política de cotas para candidaturas das mulheres.

$\mathrm{Na}$ última década, com a aproximação do Estado de um modelo mais distributivo observou-se, de um lado, a criação de organismos institucionais a serviço dos direitos humanos das mulheres e, de outro lado, a diminuição da desigualdade econômica e mobilidade social ascendente de mais de 30 milhões de pessoas (NERI, 
2010). Nos anos 2000 são identificados novos arranjos institucionais no plano de políticas do Governo Federal - notadamente a criação dos PNDH (Plano Nacional de Direitos Humanos) II e III, a criação da Secretaria Especial de Direitos Humanos e da Secretaria Especial de Políticas para as Mulheres com status de ministério, o Plano Nacional de Políticas para as mulheres (PNPM), entre outros - favoráveis às políticas públicas de gênero e promoção dos direitos humanos. Nesse contexto, foram implantadas políticas afirmativas de gênero, políticas de formalização do trabalho doméstico, políticas de combate à violência contra a mulher e à população LGBT, tais como: criação das delegacias especializadas no atendimento à mulher (DEAM), criação de juizados especiais, programa de combate à violência e à discriminação contra LGBT, aprovação da Lei Maria da Penha, criação da Central de Atendimento à Mulher, Centro de Atendimento Especializado na população LGBT, entre outras.

Entretanto, mesmo reconhecendo que houve avanços importantes, é necessário destacar que ainda são bastante altos os níveis de desigualdade de gênero, sobretudo em campos que envolvem mais prestígio e poder do espaço público, quais sejam: campos do trabalho, representação política e ciência.

\section{Desigualdade de Gênero nos Campos do Trabalho, da Representação Política e da Ciência: Avanços e Desafios}

Teoricamente, a desigualdade de gênero tem sido explicada de formas distintas, indo de abordagens funcionalistas às abordagens feministas, cujas explicações também divergem entre si. O fato já foi explicado a partir de diferenças naturais e biológicas, o que foi criticado ferrenhamente pelo feminismo, cujas vertentes liberal, radical, marxista, negra e pós-moderna contribuíram para a formação de um arcabouço teórico amplo. Assim, explicam a desigualdade 
remetendo a uma variedade de processos sociais como o patriarcado, o sexismo e o capitalismo. Não cabe aqui a análise dessas teorias, inclusive porque isso já foi feito (GIDDENS, 2012; WALBY, 1990), mas vale ressaltar algumas lições do feminismo, ou seja: nada há de natural na alocação de tarefas da sociedade, o que há são processos de socialização culturalmente determinados atribuindo papéis de gênero que confinaram as mulheres em determinadas posições marcadas pela assimetria de poder; a desigualdade deve ser visibilizada, enfrentada e superada.

\section{Desigualdade no campo do trabalho}

No campo das relações de trabalho, embora as desigualdades sigam presentes, é possível observar algumas conquistas. De acordo com dados do último censo demográfico (IBGE, 2014), constatase "aumento da participação das mulheres no mercado de trabalho brasileiro entre 2000 e 2010 ", a taxa de atividade tendo subido de $50 \%$ para $54,6 \%$. Ao longo desse período, o diferencial referente à taxa de atividade de homens e mulheres que era de aproximadamente 30 pontos percentuais caiu para 21. A despeito desse crescimento, o ritmo foi distinto em determinadas categorias examinadas, como a categoria de mulheres jovens (16 a 29 anos) e a categoria de mulheres negras.

No segmento de trabalho doméstico que representa o maior contingente de trabalhadoras da força de trabalho feminina ocupada $(15,8 \%)$ (IBGE, 2008), a precarização e estigma estão sendo combatidas, através da formalização e direitos legais adquiridos (FGTS, férias, seguro-desemprego, direito a feriados religiosos e civis, estabilidade para gestantes), regulamentados pela Emenda Constitucional número 72 , conhecida como "PEC das domésticas" ${ }^{2}$, não obstante a aplicação não generalizada e as disparidades regionais na aplicação desses direitos (IBGE, 2010b).

2 Sancionada em Junho de 2015. 
E, de acordo com dados do Comitê de Articulaçãoe Monitoramento do Plano Nacional de Políticas para as Mulheres de 2009, algumas metas estabelecidas na promulgação do Plano em 2005 foram alcançadas, tais como a elevação em 5,2\% na taxa de atividade das mulheres na PEA, entre 2003 e 2007. Conforme dados da PNAD, a taxa de atividade das mulheres aumentou de $50,7 \%$ para $52,4 \%$ em 2007. Tal como salientado pelo documento do referido Comitê, embora a meta não tenha sido inteiramente alcançada, o incremento representou mais de cinco milhões de mulheres à disposição no mercado de trabalho. Entretanto, é pertinente observar o que acontece em outros países em relação à inserção das mulheres na PEA, o que será feito com base em dados da OIT (ILO, 2010). Para tanto foram considerados países em estágios de desenvolvimento similares ao brasileiro e um representante de país mais desenvolvido. É possível observar que a inserção das mulheres brasileiras no mercado de trabalho assalariado (66\%) é pior do que países como Argentina (80,2 \%) e África do Sul (80, 8\%). Por outro lado, quando se trata de mercado informal e posições de trabalho mais vulneráveis, como é o caso das trabalhadoras domésticas, o Brasil ocupa o primeiro lugar no ranking.

Já no que tange a taxas de desemprego, média de rendimentos, distribuição de empregos com carteira de trabalho assinada e proporção de mulheres na posição de "empregadoras", as desigualdades são bastante expressivas, o que já foi ressaltado em estudos da década de 90 (GUIMARÃES, 2001; LAVINAS, 1997). Embora os níveis de escolaridade da população feminina, principalmente da população ocupada urbana, sejam superiores aos alcançados pelos homens enquanto a taxa de homens com nível superior completo é de 7,8\%, a das mulheres é de 9,2\% (IBGE, 2009) e desde 2004 há mais mulheres no país com títulos de doutorado do que homens (CENTRO DE GESTÃO E ESTUDOS ESTRATÉGICOS, 2010) - as taxas de desemprego experimentadas pelas mulheres são significativamente superiores, a 
distribuição de empregos com carteira de trabalho assinada é inferior e, por fim, a remuneração média real das empregadas com carteira assinada também se apresenta bastante inferior à masculina.

Em relação às taxas de desemprego, seja numa década de desemprego em alta (anos 90, por exemplo), seja numa década de aquecimento econômico e pleno emprego (anos 2000, por exemplo), a mão de obra feminina segue sendo mais atingida pelo desemprego, a despeito de ser esta uma mão de obra mais escolarizada.

Em se tratando dos rendimentos percebidos por homens e mulheres as diferenças são ainda maiores. De acordo com dados do IBGE, até o final dessa década "o total de mulheres ocupadas recebia cerca de 70,7\% do rendimento médio dos homens ocupados" (IBGE, 2010a). Destaque-se um dado curioso: é entre mulheres mais escolarizadas, com 12 anos de estudo ou mais, que essa razão mostrase mais baixa, não chegando aos $70 \%$ dos rendimentos masculinos, ficando em 58\% (IBGE, 2010a). A explicação pode ser remetida aos nichos considerados tradicionalmente femininos ocupados pelas mulheres e pouco valorizados no mercado de trabalho (serviço social, educação, saúde).

\section{Desigualdade no Campo da Representação política}

O campo da representação política é um dos espaços mais críticos no que tange a desigualdade de gênero. Quando se observa que as mulheres representam apenas $15 \%$ dos eleitos nos parlamentos mundiais (WALBY, 2004) tem-se a medida clara dessa ausência, que no Brasil é significativamente maior, representando $10 \%$ dos eleitos (TRIBUNAL SUPERIOR ELEITORAL, 2014). Essa ausência das esferas do poder implica num alto custo real e simbólico, o das vozes silenciadas ou ouvidas de modo tênue nas assembleias políticas fundamentais. 
Para visibilizar mais objetivamente essa desigualdade, observe-se como principal indicador a distribuição das mulheres no Congresso Nacional com base nas eleições de ocorridas em 2014. Para o cargo de deputada federal foram eleitas 51 mulheres correspondendo a 9,9\%. Já para o cargo de senadora foram eleitas 5 mulheres correspondendo a 18,5\%. Levando em conta a evolução dessa distribuição ao longo das últimas décadas, constata-se um movimento ascendente para os dois cargos, sem alcançar, contudo, crescimento significativo.

Para enfrentar esse cenário extremamente adverso, em 1996 foi implantada no Brasil a política de cotas para candidaturas de mulheres compreendendo uma grande conquista no sentido do enfrentamento da desigualdade de gênero nos espaços de representação e poder. Nos vários países onde essa política afirmativa foi adotada tem se observado crescimento da participação das mulheres em instâncias legislativas (ARAÚJO, 2002). Considerando países da América Latina, resultados mostram-se bastante positivos com aumento significativo da participação das mulheres. Em uma década, a representação feminina no parlamento subiu de 10,8\% para 18,5\%. Tomando a Argentina como exemplo, esta passou de $6 \%$ para $38 \%$. Contudo, em se tratando do Brasil, os resultados eleitorais da política de cotas têm sido bastante inexpressivos, tanto para o Senado, como para a Câmara Federal e as Câmaras Legislativas Estaduais, incluindo prefeituras. Estudos sobre eleições municipais de 1996 e para Câmara Federal em 1998, onde cotas foram adotadas, revelaram um percentual de candidatas eleitas de 11\% (ARAÚJO, 2002, p. 152). Tais estudos não destoam dos achados da última década, onde não se observa aumento da inserção das mulheres nas principais esferas de poder do país (Senado, Câmara Federal, Câmaras Estaduais) $)^{3}$. Os resultados da eleição municipal de 2008 vão na mesma direção, não contradizendo esses dados (dos

3 Mais adiante será bastante pertinente investigar a fundo o impacto simbólico e objetivo da eleição de Dilma Rousseff para Presidente do Brasil no que tange à desigualdade de gênero nas instâncias de poder. 
prefeitos eleitos apenas 9\% eram mulheres). Por fim, as eleições de 2014, como demonstrado acima, revelam resultados semelhantes.

A questão da ineficácia da política de cotas vem sendo bastante discutida por acadêmicas, militantes e candidatas (ARAÚJO, 2002; ARAÚJO; ALVES, 2007; GROSSI; MIGUEL, 2001) e algumas causas têm sido apresentadas, quais sejam: fragilidade da legislação que não pune partidos ao não cumprirem as cotas, características do sistema eleitoral e partidário (listas abertas ou listas fechadas, falta de financiamento público de campanha, diferenças entre os partidos em relação aos seus compromissos em relação às mulheres), falta de apoio financeiro e de recursos materiais, lógica sexista sobrepondo-se a propalada lógica eleitoral onde o partido verte mais apoio para o candidato com mais chances de vitória.

Assim, no âmbito da representação política, a política de cotas compreende uma conquista e um desafio. Isso porque é indiscutível que compreende um avanço em termos de instrumental institucional, todavia exige aperfeiçoamento para que de fato contribua para a equidade de gênero nesse campo.

No sentido desse aperfeiçoamento não se pode perder de vista os dispositivos introduzidos pela Lei no 12.034/09 à legislação eleitoral, os quais trataram de alterar o termo "reserva" para "preenchimento" de vagas. Fato que impactou sobre o pleito de 2014 (28,9\%) com crescimento do número de candidaturas femininas em relação ao pleito de 2010 (22,4\%) (TRIBUNAL SUPERIOR ELEITORAL, 2014). No futuro, será importante investigar os impactos efetivos do novo entendimento jurisprudencial.

\section{Desigualdade de gêNero No CAMPo Científico}

E como anda a desigualdade de gênero no campo científico brasileiro? Para traçar um breve esboço do cenário, utilizam-se dados 
do $\mathrm{CNPq}$, recorrendo principalmente aos seguintes indicadores: distribuição dos pesquisadores por sexo, por liderança em grupos de pesquisa e por bolsistas de produtividade.

Historicamente, a relação entre mulheres e ciência foi marcada, ora pela negação formal e institucional da inserção das mulheres no campo científico, ora pela forte tendência à obliteração das suas contribuições. É importante ressaltar que a teoria social clássica - um bom exemplo é o caso de Rousseau, em seu Emílio - tem uma dívida com as mulheres, visto que não somente expressou os valores da cultura androcêntrica, como ajudou a fortalecê-los, disseminando a ideia de que haveria uma incompatibilidade - cognitiva e social - entre a ciência e as mulheres. De maneira que o nosso lugar na comunidade científica foi em grande medida um não-lugar, ou, quando muito, o lugar de assistentes do saber.

Todavia, a despeito do cenário adverso, atualmente é maior o percentual de mulheres entrando nas universidades, concluindo curso superior e com títulos de doutorado. De acordo com dados do INEP, no início dos anos 2000, as mulheres já representavam $62 \%$ do total de concluintes no ensino universitário (LETA, 2003). Passada mais de uma década, o dado permaneceu sem alterações significativas. Portanto, quando barreiras institucionais e sociais à escolarização são removidas e condições estruturais são conquistadas observa-se a tomada de espaço pelas mulheres, o que já tinha sido defendido no século XV por Christine de Pizan, em sua La Cité des Dames.

Entretanto, ainda persiste a ideia da ciência como não-lugar das mulheres, por, supostamente, faltar "capacidade inata" para o fazer científico, percepção expressa inclusive por representantes prestigiados do meio científico, como ilustrado pelo caso Larry Summers. A sub-representação das mulheres em importantes esferas do campo científico não raro é vinculada a questões de gosto, vocação, menor capacidade para raciocínio abstrato, comportamentos dominados pela 
subjetividade/emoção em lugar da objetividade/razão, incapacidade de conciliar atividade científica, família e maternidade, entre outros. De maneira que recairia sobre as mulheres a responsabilidade por sua ausência ou invisibilidade, resultantes de suas escolhas pessoais e menor capacidade inata. A "culpa" ou o peso da ausência incidiria assim sobre o indivíduo e não sobre as estruturas sociais e culturais que delimitam escolhas, impondo condições institucionais difíceis de serem transpostas.

Passados cerca de cinquenta anos desde a publicação do agora clássico "Women in Science: Why so Few?", de Alice Rossi, e considerando o caso brasileiro, a questão deve ser reformulada. Não se trata mais de perguntar "por que tão poucas", mas de analisarmos por que tão poucas nos espaços de maior poder e prestígio do campo científico? Isso porque ao se analisar os dados, constatam-se avanços no sentido da conquista da equidade, contudo a segregação vertical e horizontal permanece. De acordo com o CNPq (2013), no que tange à distribuição de pesquisadores por áreas de conhecimento, observa-se a presença majoritária das mulheres nas Ciências Humanas (na área de educação o percentual é de 67\%) e relativo equilíbrio nas Ciências da Saúde e Ciências Biológicas, embora algumas áreas como fonoaudiologia (89\%) e enfermagem (87\%) também haja predomínio das mulheres. A segregação horizontal permanece nas Ciências Exatas, principalmente nas engenharias, computação e física. Em engenharia mecânica o percentual é de 14\%, engenharia elétrica, naval e oceânica é de 13\%, em física o percentual é de $20 \%$. O caso da computação, examinado por Lima (2013), revela uma das áreas de maior segregação horizontal, a concentração masculina chegando a $80 \%$. Ademais, além de reduzida, a inserção das mulheres nessa área tem diminuído desde a década de 1990, fenômeno presente no Brasil, mas também em outros países como EUA e Canadá. 
Já no que se refere à distribuição geral de pesquisadores por sexo, desde 2010 a equidade foi alcançada. Entretanto, quando se observa os dados sobre pesquisadores líderes de grupos de pesquisa (nessa esfera de maior prestígio científico as mulheres ocupam espaço minoritário, representando $45 \%$ dos pesquisadores líderes) e bolsistas de produtividade a desigualdade permanece, embora haja aumento progressivo da participação das mulheres nos últimos anos. No caso dos bolsistas de produtividade, entre 2001 e 2011, o percentual geral de mulheres bolsistas foi de $32 \%$ a $35 \%$. Note-se que no nível mais alto, o $1 \mathrm{~A}$, o percentual é ainda mais baixo, tendo variado de $22 \%$ a $23 \%$.

Em suma, tanto no que se refere ao acesso e resultados da educação formal como do campo científico, nota-se avanços consideráveis, entretanto, quando o foco é a área das ciências exatas ou as instâncias de maior prestígio do fazer científico - as bolsas de produtividade, por exemplo - a desigualdade de gênero persiste. É fundamental que políticas sejam implementadas a fim de conquistar a equidade. Políticas de incentivo ao ingresso das meninas para as ciências exatas já a partir do ensino fundamental podem contribuir para enfrentar os obstáculos, apontando alternativas, encorajando sonhos e projetos, ampliando as oportunidades e o leque de escolhas para definição de trajetórias de vida e carreiras.

\section{Conquistas e Desafios}

Em suma, no campo do trabalho há conquistas no que tange ao aumento na participação das mulheres na PEA (população economicamente ativa), à formalização legal de direitos para trabalhadores domésticos e ao aumento da qualificação profissional decorrente de níveis de escolaridade mais altos. Em contrapartida, a desigualdade salarial é um desafio a ser superado, bem como a maior vulnerabilidadeà condição de desemprego. No campo da representação 
política a política de cotas compreende um avanço em termos de instrumental institucional para enfrentar a desigualdade, contudo ainda éimprescindível buscar meios para tornar esse instrumental mais eficaz. No campo científico a equidade foi conquistada em algumas áreas de conhecimento, entretanto a desigualdade permanece em grande medida nas ciências exatas e nas instâncias mais prestigiadas do fazer científico.

Para dar conta do quadro de desigualdade persistente, políticas públicas de gênero são fundamentais. A eficácia dessas políticas não é uma questão simples, dependendo de vários fatores. Em primeiro lugar, depende de fatos que antecedem sua formulação, como estar em sintonia com as principais demandas das mulheres, expressas nas ações e discurso dos movimentos sociais. Em segundo lugar, depende do modo de formulação, ou seja, se tem as mulheres apenas como beneficiárias ou se essas participam ativamente do processo de formulação e implementação dessas políticas atuando como sujeitas de transformação. Em terceiro lugar, é crucial que tenham em sua essência compromisso real com a equidade de gênero. Por fim, há também que ter em vista um mecanismo complexo e necessário na formulação dessas políticas, qual seja: a articulação entre políticas redistributivas e políticas de reconhecimento (FRASER, 2001).

\section{CONSIDERAÇões Finais}

O breve estudo ora apresentado está longe de esgotar a questão da desigualdade de gênero e políticas públicas, contudo alcança seus objetivos preliminares de lançar luz sobre a problemática proposta.

Sem políticas públicas de gênero a equidade corre o risco de ser reduzida a mera utopia. Houve avanços quando a questão é desigualdade de gênero ou desrespeito aos direitos humanos das 
mulheres. Entretanto, tais avanços não reverteram o quadro de desigualdade em vários campos, sobretudo naqueles discutidos acima.

Urge que determinadas ideias sejam combatidas - da ciência ou da política como não-lugar para as mulheres baseada numa suposta inaptidão cognitiva e psicossocial das mesmas - à luz de uma compreensão mais profunda da realidade. Às vezes aquilo que deveria ser óbvio é enclausurado numa gaiola de ignorância que teima em existir por séculos e séculos. E o que deveria ser óbvio? Que a desigualdade de gênero não resulta de inaptidão cognitiva ou social, mas de uma socialização de gênero que delimita papéis e horizontes de possibilidades para homens e mulheres e de estruturas sociais que perpetuam e limitam oportunidades e obstáculos. Por fim, a transformação dessas condições depende de uma coalizão de forças entre sociedade civil e Estado, através da ação dos movimentos sociais e políticas públicas de gênero eficazes.

\section{REFERÊNCIAS}

ALVAREZ, Sonia. Falas do Estado ou o estado das falas sobre as mulheres nas administrações democrático-populares. In: TATAU, Godinho; SILVEIRA, Maria Lúcia. (Org.). Políticas públicas e igualdade de gênero. São Paulo: Coordenadoria Especial da Mulher, 2004. p. 103-111.

ARAÚJO, Clara. Ações afirmativas como estratégias políticas feministas. In: BRUSCHINI, Cristina; UNBEHAUM, Sandra G. (Org.). Gênero, democracia e sociedade brasileira. São Paulo: Ed. 34, 2002. p. 143-166.

ARAÚJO, Clara; ALVES, José E. D. Impactos de indicadores sociais e do sistema eleitoral sobre as chances das mulheres nas eleições e suas interações com as cotas. DADOS: Revista de Ciências Sociais, Rio de Janeiro, v. 50, n. 3, p. 535-57, 2007.

BESSE, Susan. Modernizando a desigualdade. São Paulo: EDUSP, 1999.

CENTRO DE GESTÃO E ESTUDOS ESTRATÉGICOS - CGEE. Doutores 2010: estudo da demografia da base técnico-científica brasileira. Brasília: CGEE, 2010.

CNPq. Número de mulheres cientistas já iguala o de homens. 2013. Disponível em: $<$ http://www.cnpq.br/web/guest/noticiasviews/journal_content/56_INSTANCE_ a6MO/10157/905361>. Acesso em: 5 abr. 2014. 
FARAH, Marta F. Gênero e políticas públicas na esfera local de governo. Organizações \&Sociedade, Salvador, v. 6, n. 14, p. 65-104, jan./abr. 1999.

FARAH, Marta F. Gênero e políticas públicas. Estudos Feministas, Florianópolis, n. 12, v. 1, p. 47-71, jan./abr. 2004.

FRASER, Nancy. Da redistribuição ao reconhecimento: dilemas da justiça na era pós-socialista. In: Democracia hoje: novos desafios para a teoria democrática contemporânea (Org. Jessé Souza). Brasília: Editora UNB, 2001.

GIDDENS, Anthony. Sociologia. Porto Alegre: Penso, 2012.

GOETZ, Ane Mari. The politics of integrating gender to state development processes: trends, opportunities and constraints in Bangladesh, Chile, Jamaica, Mali, Morocco and Uganda. United Nations Research Institute for Social Development United Nations Development, Geneva, 1995.

GROSSI, Miriam P.; MIGUEL, Sonia M. Transformando a diferença: as mulheres na política. Estudos Feministas, Florianópolis, v. 9, n. 1, p. 167-206, 2001.

GUIMARÃES, Nadya.Laboriosas mas redundantes: gênero e mobilidade no trabalho no Brasil dos 90. Estudos Feministas, Florianópolis, v. 9, n. 1, p. 82-102, 2001.

IBGE. Censo demográfico 2010a. Disponível em: <http://www.censo2010.ibge.gov. br>. Acesso em: 2 abr. 2014.

IBGE. Estatísticas de gênero: uma análise do censo demográfico de 2010. Rio de Janeiro, 2014. Disponível em: <http://biblioteca.ibge.gov.br/visualizacao/livros/ liv88941.pdf>. Acesso em: 9 out. 2015.

IBGE. Pesquisa nacional por amostra de domicílios: síntese de indicadores 2008. Disponível em: <http://www.ibge.gov.br/home/estatistica/populacao/ trabalhoerendimento/pnad2008/>. Acesso em: 9 abr. 2014.

IBGE. Pesquisa nacional por amostra de domicílios: síntese de indicadores 2009. Disponível em: <http://www.ibge.gov.br/home/estatistica/populacao/ trabalhoerendimento/pnad2009/>. Acesso em: 9 abr. 2014.

IBGE. Pesquisa nacional por amostra de domicílios: síntese de indicadores 2010b. Disponível em: <http://www.ibge.gov.br/home/estatistica/populacao/ condicaodevida/indicadoresminimos/sinteseindicsociais2010/SIS_2010.pdf>. Acesso em: 9 abr. 2014.

ILO. Laborsta internet. Genebra, 2010. Disponível em: <http://laborsta.ilo.org/>. Acesso em: 8 ago. 2010. 
LAVINAS, Lena. Emprego feminino: o que há de novo e o que se repete. Dados, Rio de Janeiro, v. 40, n. 1, p. 41-67, 1997.

LETA, Jacqueline. As mulheres na ciência brasileira: crescimento, contrastes e um perfil de sucesso. Estudos Avançados, São Paulo, v. 17, n. 49, p. 271-284, 2003.

LIMA, Michelle P. As mulheres na ciência da computação. Estudos Feministas, Florianópolis, v. 21, n. 3, p. 496, set./dez. 2013.

MARSHALL, Thomas Humphrey. Social policy in the twentieth century. 2. ed. Londres: Hutchinson, 1967.

MOGHADAM, Valentine. Transnational feminist networks. International sociology SAGE, London, v. 15, n. 1, 2000.

NASCIMENTO, Janaína Xavier. Para uma teoria da identidade na modernidade: mudanças e permanências à luz do reconhecimento e do feminismo. 2005. $180 \mathrm{f}$. Tese (Doutorado em Sociologia Política) - Universidade Federal de Santa Catarina, Florianópolis, 2005.

NERI, Marcelo Cortes (Coord.). A nova classe média: o lado brilhante dos pobres. 3. ed. Rio de Janeiro: FGV/CPS, 2010.

SANTOS, Boaventura de Sousa. Por uma concepção multicultural de direitos humanos. In: FELDMAN-BIANCO, Bianco; CAPINHA, Graça (Org.). Identidades: estudos de cultura e poder. São Paulo: Hucitec, 2000.

SCHERER-WARREN, Ilse. Redes de movimentos sociais. São Paulo: Edições Loyola, 1993.

TRIBUNAL SUPERIOR ELEITORAL - TSE. Estatísticas eleitorais 2014. Brasília: TSE, 2014. Disponível em: <http://goo.gl/L2aDkX>. Acesso em: 13 nov. 2014.

WALBY, Sylvia. Cidadania e transformações de gênero. In: TATAU, Godinho; SILVEIRA, Maria Lucia (Org.). Políticas públicas e igualdade de gênero. São Paulo: Coordenadoria Especial da Mulher, 2004. p. 169-182.

WALBY, Sylvia. Theorizing patriarchy. Oxford: Blackwell, 1990. 